\title{
Comparative Analyses of the Transport Proteins Encoded within the Genomes of nine Bifidobacterium Species
}

\author{
Hassan Zafar ${ }^{a, b}$ Milton H. Saier Jr. ${ }^{a}$ \\ aDepartment of Molecular Biology, Division of Biological Sciences, University of California at San Diego, La Jolla, CA, USA; \\ ${ }^{b}$ Central European Institute of Technology, Masaryk University, Brno, Czech Republic
}

\section{Keywords \\ Bifidobacterium - Molecular transport - Gut microbiome · Genome · Proteome · Probiotic · Pathogenic · Toxins · Drug resistance}

\begin{abstract}
The human microbiome influences human health in both negative and positive ways. Studies on the transportomes of these organisms yield information that may be utilized for various purposes, including the identification of novel drug targets and the manufacture of improved probiotic strains. Moreover, these genomic analyses help to improve our understanding of the physiology and metabolic capabilities of these organisms. The present study is a continuation of our studies on the transport proteins of the major gut microbes. Bifidobacterium species are essential members of the human gut microbiome, and they initiate colonization of the gut at birth, providing health benefits that last a lifetime. In this study we analyze the transportomes of nine bifidobacterial species: $B$. adolescentis, $B$. animalis, $B$. bifidum, $B$. breve, $B$. catenulatum, $B$. dentium, $B$. longum subsp. infantis, $B$. longum subsp. longum, and B. pseudocatenulatum. All of these species have proven probiotic characteristics and exert beneficial effects on human health. Surprisingly, we found that all nine of these species have similar pore-forming toxins and
\end{abstract}

karger@karger.com www.karger.com/mip

Karger $\stackrel{\text { ' }}{5}$

GOPEN ACCESS
(C) 2021 The Author(s)

Published by S. Karger AG, Basel

This is an Open Access article licensed under the Creative Commons Attribution-NonCommercial-4.0 International License (CC BY-NC) (http://www.karger.com/Services/OpenAccessLicense), applicable to the online version of the article only. Usage and distribution for commercial purposes requires written permission. drug exporters that may play roles in pathogenesis. These species have transporters for amino acids, carbohydrates, and proteins, essential for their organismal lifestyles and adaption to their respective ecological niches. The strictly probiotic species, B. bifidum, however, contains fewer such transporters, thus indicative of limited interactions with host cells and other gut microbial counterparts. The results of this study were compared with those of our previous studies on the transportomes of multiple species of Bacteroides, Escherichia coli/Salmonella, and Lactobacillus. Overall, bifidobacteria have larger transportomes (based on percentages of total proteins) than the previously examined groups of bacterial species, with a preference for primary active transport systems over secondary carriers. Taken together, these results provide useful information about the physiologies and pathogenic potentials of these probiotic organisms as reflected by their transportomes. @ 2021 The Author(s)

Published by S. Karger AG, Basel

\section{Introduction}

The genus Bifidobacterium is well represented in human gut microbiomes, particularly those of breast-fed infants. Members of this genus are among the first bacterial species to colonize the infant gut and may also reside
Correspondence to:

Hassan Zafar, hassan.zafar@ ceitec.muni.cz Milton H. Saier Jr., msaier@ ucsd.edu 
in other anatomical locations including the oral cavity and genitourinary tract [O'Callaghan et al., 2016]. Bifidobacteria are Gram-positive, anaerobic/microaerophilic, heterofermentative, non-spore-forming, and non-motile actinobacteria [Pokusaeva et al., 2011]. Based on their metabolic characteristics, they are often included among the low $\mathrm{G}+\mathrm{C}$ lactic acid bacteria group of firmicutes, despite being phylogenetically within the high $\mathrm{G}+\mathrm{C}$ (DNA $\mathrm{G}+\mathrm{C}$ content of 55-67\%) of the actinobacteria [Bintsis, 2018]. These organisms may show various human-related characteristics such as commensal, probiotic, and/or opportunistic pathogenic. The morphologies of the species in this genus are characterized by their irregular V-or Y-shaped rods with rudimentary branching [Butta et al., 2017]. Past research indicated that populations of these bacteria thrive in the gut of infants fed with human breast milk and decrease in numbers with the introduction of cow's milk-based formula [Nolan et al., 2020]. Several bifidobacterial growth-promoting factors such as lactulose and human milk oligosaccharides seem to be responsible for the association of high numbers of these gut bacteria with the feeding of babies with human breast milk [Lee and Sullivan, 2010]. The increase in bifidobacterial populations in infants correlates with the suppression of growth of pathogenic microbes in the gut [Bullen et al., 1976]. Thus, an increase in the population of the members of this genus is considered to provide health benefits during early development of the human gut, and possibly throughout life [Vitetta et al., 2018].

Various species of Bifidobacterium are used routinely as probiotics and are considered to be important components of a healthy gut [Kosmerl et al., 2021]. There are numerous potential mechanisms responsible for the probiotic actions of these species. Members produce various metabolites, such as short-chain fatty acids and polyunsaturated fatty acids, providing nutrition for the host, as well as hydrogen peroxides that inhibit the growth of some pathogenic bacteria [Matsuki et al., 2013; Sugahara et al., 2015]. Bifidobacterial species also produce other organic acids, preventing the growth and colonization of pathogens that are acid sensitive and/or putrefactive [Fukuda et al., 2011].

Another important component of the probiotic repertoire of these species is the release of bacteriocins. These microbial peptides exert antibacterial effects against certain Gram-positive and Gram-negative bacterial pathogens. The bacteriocins encoded by Bifidobacterium spp. are thermostable (at temperatures of at least $80^{\circ} \mathrm{C}$, and often as high as $100^{\circ} \mathrm{C}$ ) and have been shown to be effective in inhibiting antibiotic-resistant strains of cancer-causing
Helicobacter pylori [Collado et al., 2005]. Various bifidobacteria also exert anti-cancer effects on various transformed cell lines [Pool-Zobel et al., 1996; Tayan et al., 2002; O'Callaghan et al., 2016]. Studies on the immunomodulatory actions of these species have shown that they can influence the effects of T-regulatory cells and dendritic cells. Other reported immunostimulatory actions include regulation of cytokine expression, enhancement of immunoglobulin A production, and increases in the activities of natural killer cells and macrophages [Shang et al., 2020].

Bifidobacterium spp. may assume the role of opportunistic pathogens due to a disturbance in their normal gut ecological niches and/or translocation to other bodily sites. Various species have been associated with bacteremia, infections of the genitourinary tract, pleuropulmonary infections, and dental caries [Green, 1978; Weber et al., 2015]. Most documented infections in humans are caused by $B$. longum and B. dentium [Esaiassen et al., 2017], with pathogenesis dependent on acidity and the immune status of the host [Nakajo et al., 2010].

The transportomes of bacterial residents of the human gut play a wide array of physiological, metabolic, and pathogenic roles. Our previous projects on other bacterial gut residents (Escherichia, Salmonella, Bacteroides, and Lactobacillus) [Tang and Saier, 2014; Do et al., 2017; Zafar and Saier, 2018; Zafar and Saier, 2020] unveiled interesting details regarding the potential roles played by transport proteins. From ecological standpoints, our findings suggested that: (i) gut bacteria utilize their transport proteins to promote various ecological interactions, (ii) the transportomes of many species are finely tuned according to their organismal lifestyles (extra- vs. intracellular sites of growth; commensal, probiotic, and/or pathogenic), and (iii) species with transporters specific to their ecological niche tend to thrive better in comparison to other gut bacterial counterparts.

In the present communication, similar analyses with nine species of Bifidobacterium are reported. All the analyzed species are normal residents of the mammalian gut, but some may also reside in the vagina, the oral cavity, and/or various other bodily sites [Xiao et al., 2021]. All nine species have established beneficial effects on human health, although as noted above, some have the potential to cause pathogenesis, particularly in non-intestinal locations of the human body (Table 1) [Wong et al., 2020]. Some of these probiotic organisms may play roles in detoxification needed when heavy metals are present [Abdel-Megeed et al., 2021], while others have beneficial implications with respect to the pathogenesis of breast cancer and other cancerous types [Fernandez et al., 2020; Saman- 
Table 1. Overview of the 9 Bifidobacterium species included in this study

\begin{tabular}{|c|c|c|c|c|c|c|}
\hline Strain & $\begin{array}{l}\text { Abbre- } \\
\text { viation }\end{array}$ & Accession No. & $\begin{array}{l}\text { Genome } \\
\text { size, Mbp }\end{array}$ & $\begin{array}{l}\text { Total transport } \\
\text { proteins } \\
\text { identified }\end{array}$ & $\begin{array}{l}\text { Transport } \\
\text { proteins, } \% \text { of } \\
\text { total proteins }\end{array}$ & Location in host \\
\hline B. adolescentis ATCC 15703 [Turroni et al., 2010] & Bad & AP009256.1 & 2.08 & 273 & 12.3 & GIT \\
\hline B. animalis subsp. Lactis DSM 10140 & Ban & СР001606.1 & 1.93 & 253 & 15.9 & GIT, breast milk \\
\hline B. bifidum PRL2010 & Bbi & NC_014638 & 2.22 & 240 & 13.8 & GIT \\
\hline B. breve JCM 7017 [van de Guchte et al., 2006] & $\mathrm{Bbr}$ & NZ_CP006712 & 2.29 & 350 & 19.4 & GIT \\
\hline B. catenulatum DSM 16992 [Morita et al., 2015] & Bca & NZ_AP012325.1 & 2.07 & 301 & 18.6 & GIT \\
\hline B. dentium JCM 1195 [Toh et al., 2015] & Bde & NZ_AP012326 & 2.64 & 403 & 19.3 & GIT, oral cavity \\
\hline B. longum subsp. infantis ATCC 15697 [Sela et al., 2008] & Bli & NC_011593.1 & 2.83 & 380 & 15.8 & GIT \\
\hline B. longum subsp. longum strain JCM 1217 [Fukuda et al., 2011] & Blo & AP010888.1 & 2.38 & 308 & 13.8 & GIT \\
\hline B. pseudocatenulatum strain 12 & Bps & NZ_CP025199.1 & 2.19 & 311 & 18.7 & GIT \\
\hline
\end{tabular}

Information about the pathogenic and non-pathogenic potential of the species is inferred on the basis of data adapted from Esaiassen et al. [2017]. GIT, gastrointestinal tract.

ta, 2020]. Additionally, it has been reported that supplementation with probiotic bacteria improves the health of overweight and obese patients [Wicinski et al., 2020] and combats Crohn's disease, as well as several other harmful conditions [Dudek-Wicher et al., 2020], including various types of allergies [Cukrowska et al., 2020]. Recent reports also suggest that these organisms may positively influence cognitive and behavioral functions in animals and humans [Ruiz-Gonzalez et al., 2020]. Moreover, bifidobacterial species appear to contribute to the control of (corona) virus diseases [Buzkort et al., 2020; Tiwari et al., 2020], and the use of probiotic strains have been considered for the prevention of necrotizing enterocolitis in preterm and low birth weight infants [Sharif et al., 2020].

A general introduction to the properties of the nine species, including their strain designations, abbreviations to be used, genome accession numbers, genome sizes in megabase pairs, total numbers and percentages of transport proteins identified, and locations in the human body are summarized in Table 1. However, a suggestion emerging from results presented in the current study is that these probiotic species may be associated with currently unrecognized disease conditions as noted above and since they contain many homologs of known disease-causing toxic proteins and multidrug resistance pumps.

Possibly, all bifidobacteria considered here have the potential to influence human health in two opposite ways, and thus have bidirectional potential. We identified a number of pore-forming protein/peptide toxins synthesized by these species that may contribute to their probiotic properties (e.g., by inhibiting the growth of and/or toxin production by pathogens, viruses, and/or eukaryotic pathogens) or their pathogenicities (e.g., when inhib- iting the growth, well-being, and/or essential interactions of host cells). The identification of these proteins and peptides is likely to allow the engineering of bifidobacteria with enhanced probiotic and diminished pathogenic potential [Yuan et al., 2020; Zuo et al., 2020] as well as strains with the capability of combating disease to an even greater extent than current naturally occurring species.

\section{Materials and Methods}

\section{Genome-BLAST Searches of Bifidobacterial Proteomes}

Three of the species selected, B. longum, B. animalis, and $B$. adolescentis are type strains, while the remaining genomes were selected on the basis of their draft quality and completeness. The nine proteomes (details of genomes are given in Table 1) were screened for homologs of all proteins in the Transporter Classification Database (TCDB; www.tcdb.org) in December 2020 and April 2021 using G-BLAST [Reddy and Saier, 2012]. For each protein, the program retrieves information for both the genome query and TC top hit, the TC number of the latter, the numbers of amino acyl residues (aas) and numbers of predicted transmembrane segments (TMSs) in both proteins, the query versus hit e-value, regions of sequence similarity, and regions of TMS overlap between the query and hit proteins. For prediction of the number of TMSs, G-BLAST uses the Web-based Hydropathy, Amphipathicity and Topology (WHAT) program, which aligns the plots of hydrophobicity, amphipathicity, and similarity throughout the lengths of the two proteins [Zhai et al., 2001; Ikeda et al., 2002]. Proteins without TMSs were not omitted, as multicomponent systems often possess soluble components that are essential transport system constituents.

Examination of Distant Transport Protein Homologues of the Bifidobacterium spp.

For G-BLAST searches, we initially used an arbitrary e-value cut-off value of 0.0001 . Manual examination of the remaining proteins (having e-values of $>0.0001$ ) was conducted using topological data and by conducting further BLAST searches to determine if the
Zafar/Saier Jr. 
Table 2. Overview of Bifidobacterium transport proteins with TC subclasses

\begin{tabular}{|c|c|c|c|c|c|c|c|c|c|}
\hline TC subclass and description & \multicolumn{9}{|c|}{ Protein numbers/organism } \\
\hline 1.C, PFTs & 4 & 5 & 6 & 5 & 4 & 5 & 5 & 5 & 4 \\
\hline 1.E, holins & 0 & 3 & 2 & 2 & 3 & 1 & 6 & 1 & 3 \\
\hline 1.W, phage portal proteins & 0 & 0 & 1 & 0 & 5 & 3 & 3 & 0 & 0 \\
\hline 3.B, decarboxylation-driven transporters & 1 & 1 & 1 & 1 & 2 & 1 & 1 & 1 & 1 \\
\hline 3.D, oxidoreduction-driven transporters & 5 & 5 & 7 & 7 & 8 & 6 & 6 & 7 & 7 \\
\hline 4.A, phosphotransfer-driven group translocators (PTS) & 1 & 0 & 10 & 10 & 1 & 1 & 3 & 1 & 1 \\
\hline 4.C, acyl-CoA ligase-coupled transporters & 4 & 4 & 5 & 4 & 4 & 4 & 4 & 4 & 4 \\
\hline 4.D, polysaccharide synthase exporters & 0 & 0 & 2 & 1 & 1 & 1 & 0 & 1 & 0 \\
\hline 4.F, choline/ethanolamine phosphotransferase 1 (CEPT1) & 2 & 3 & 0 & 2 & 3 & 3 & 1 & 2 & 3 \\
\hline 9.B, putative transport proteins & 19 & 29 & 30 & 27 & 20 & 38 & 32 & 30 & 28 \\
\hline Total & 273 & 253 & 240 & 350 & 301 & 403 & 380 & 308 & 311 \\
\hline
\end{tabular}

proteins were either true homologues or false positives. As two proteins displaying homology in hydrophilic regions can give small e-values, it was necessary to manually examine the regions of overlap to prevent the selection of proteins that had good scores but were not actually homologous in their transmembrane regions. The hydropathy profiles generated by the WHAT program were used to determine whether the program had missed a TMS or predicted a TMS in an incorrect region. By using the AveHAS program, topological predictions were confirmed with much greater reliance, based on plots in which the data for several homologues were averaged [Zhai et al., 2001]. Proteins that had moderate e-values, between 0.0001 and $\mathrm{e}^{-8}$, indicated a range in which the presence of distant protein homologs was possible, and hence, they were examined further using the aforementioned steps.

\section{Identification of Substrates Transported}

Authentic transport protein homologues in the Bifidobacterial species were assigned substrates according to the assigned substrates of the TCDB hit entries. The scientific literature was also used to deduce the substrates and energy coupling mechanisms. Much of this literature is summarized and evaluated in TCDB. In addition, we also used PaperBlast [Price and Arkin, 2017] for further information about proteins.

Occurrence of Multicomponent Systems

Our analyses identified many multicomponent transport systems encoded within the nine Bifidobacterium genomes. Identification was primarily based on the presence of the transmembrane proteins of the systems; however, in some instances, other constituents were found, and when essential for the activity of the TC hit protein, they were appropriately assigned a function. If the transmembrane protein(s) was/were identified, even in the case of multicomponent systems, the transport system was considered to be present.

\section{Results}

\section{Subclasses of Transport Proteins}

The analyses of the occurrence of transport proteins in the nine Bifidobacterium spp. were conducted using the methodologies described in the Methods section. The distribution of subclasses of transport proteins identified in the nine species is given in Table 2. For complete results of our analyses, see the online supplementary Table S1 (see www.karger.com/doi/10.1159/000518954 for all online suppl. material).

\section{$\alpha$-Type Channel Proteins (TC Subclass 1.A)}

The numbers of a-type channels identified in the nine Bifidobacterium spp. considered here range from 11 to 19 per organism, with Bde having the most. All nine species seem to possess a single ammonium channel of the Ammonium Channel Transporter (Amt) family (TC\# 1.A.11); the proteins are homologs of TC\# 1.A.11.1.3, which is a low affinity ammonium uptake channel of Corynebacterium glutamicum [Walter et al., 2008]. With the exception of Bli, the remaining species have at least one member of the Large Conductance Mechanosensitive Ion Channel (MscL) family (TC\# 1.A.22); these channels catalyze the release of small proteins, ions, and osmolytes upon hypoosmotic shock [Iscla et al., 2011]. Members of the CorA Metal Ion Transporter (MIT) Family (TC\# 1.A.35) seem to be pres- 
Table 3. Occurrence of PFTs in the nine Bifidobacterium species analyzed here

\begin{tabular}{|c|c|c|c|c|c|c|c|c|c|c|c|}
\hline \multirow[t]{2}{*}{ TCID } & \multirow[t]{2}{*}{ Family } & \multirow[t]{2}{*}{ Function } & \multirow[t]{2}{*}{ Bad } & \multicolumn{8}{|c|}{ Proteins/organism, $n$} \\
\hline & & & & Ban & Bbi & $\mathrm{Bbr}$ & Bca & Bde & Bli & BII & Bps \\
\hline 1.C.1.2.4 & The channel-forming Colicin (Colicin) family & Pore formation & 0 & 0 & 1 & 0 & 0 & 0 & 0 & 0 & 0 \\
\hline 1.C.82.1.1 & Pore-forming amphipathic Helical Peptide HP(2-20) (HP2-20) family & Pore formation & 1 & 1 & 1 & 1 & 1 & 1 & 1 & 1 & 1 \\
\hline 1.C.95.1.8 & Pore-forming ESAT-6 Protein (ESAT-6) family & Pore formation & 1 & 1 & 1 & 1 & 1 & 1 & 1 & 1 & 1 \\
\hline 1.C.109.1.2 & Bacterial hemolysin A (B-hemolysin A) family & Pore formation & 1 & 0 & 1 & 1 & 1 & 1 & 1 & 1 & 1 \\
\hline 1.C.109.1.4 & Bacterial hemolysin A (B-hemolysin A) family & Pore formation & 0 & 1 & 0 & 0 & 0 & 0 & 0 & 0 & 0 \\
\hline 1.C.113.1.6 & Hly III (Hly III) family & Pore formation & 1 & 2 & 2 & 2 & 1 & 1 & 2 & 2 & 1 \\
\hline 1.C.126.1.2 & HlyC (HlyC) family of hemolysins & Pore formation & 0 & 0 & 0 & 0 & 0 & 1 & 0 & 0 & 0 \\
\hline
\end{tabular}

ent in all nine species; proteins of this family take up divalent cations, especially $\mathrm{Mg}^{2+}$, but also sometimes $\mathrm{Cd}^{2+}$, $\mathrm{Co}^{2+}, \mathrm{Ni}^{2+}$, and $\mathrm{Zn}^{2+}$. Proteins of the Camphor Resistance or Fluoride Channel (Fluc) family (TC\# 1.A.43) are present in all nine species. These fluoride ion $\left(\mathrm{F}^{-}\right)$export channels prevent fluoride toxicity by reducing the cytoplasmic concentrations of this anion [Stockbridge et al., 2013].

Other channel protein families represented in the Bifidobacterium species include the Major Intrinsic Protein (MIP) family (TC\# 1.A.8) of aquaporins and glycerol facilitators, the Calcium Transporter A (CaTA) family (TC\# 1.A.14), and the cation channel-forming Heat Shock Protein-70 (Hsp70) family (TC \#1.A.33). Hsp70 chaperone proteins include members that have been shown to form transmembrane ion-conducting channels only in eukaryotes, and it is not known if they can do so in prokaryotes. Their primary functions include chaperoning protein folding, membrane insertion, and forming heterotypic and homotypic associations [Mayer et al., 2005].

Members of the Homo-Trimeric Cation Channel (TRIC) family (TC\# 1.A.62), the Cyclin $\mathrm{M} \mathrm{Mg}^{2+}$ Exporter (CNNM) family (TC\# 1.A.112), and the pore-forming NADPH-dependent 1-Acyldihydroxyacetone Phosphate Reductase (Ayr1) family (TC\# 1.A.115) were all found to be encoded within at least some of the nine bifidobacterial genomes. Overall, eleven different channel protein families proved to be represented in the nine species. No member of the currently recognized outer membrane porin families (TC subclass 1.B) was identified, suggesting that bifidobacteria use types of outer membrane porins different from those identified in Gram-negative bacteria and other actinobacteria.

\section{Pore-Forming Toxins (TC Subclass 1.C)}

Pore-forming toxins (PFTs) are considered to be important virulence factors in both Gram-positive and
Gram-negative bacteria [Los et al., 2013]. The number of recognized PFTs encoded per bifidobacterial genome ranges from 4 to 6 . Details of the PFTs observed in the nine species are provided in Table 3. A PFT that seems to be present in all of these species corresponds to TC\# 1.C.82.1.1, a protein of the pore-forming Amphipathic Helical Peptide (HP2-20) family. Proteins of this family cause pore formation in the cell membranes of bacteria and fungi, and they thus may contribute to the probiotic potential of a bacterial spp. encoding them. With the exception of Ban, the bifidobacterial species also have homologs of TC\# 1.C.109.1.2, a hemolysin of Streptomyces coelicolor, called an S-hemolysin. This hemolysin has cytolytic activity against human fibroblasts and has been predicted to assist in nutrient and iron acquisition by the bacteria [Rajesh et al., 2013]. The presence of S-hemolysin homologs may suggest an unrecognized pathogenic potential in some of these species.

All nine bifidobacterial species examined have homologs of TC\# 1.C.95.1.8, a member of the pore-forming ESAT-6 Protein (ESAT-6) family (TC\# 1.C.95.1.8). Members of this family function in pathogenic protein secretion, again suggesting pathogenic potential for all of these species. Another hemolysin type that seems to be present in all of the examined species is TC\# 1.C.113.1.6, a member of the Hly III family (TC\# 1.C.113), thus indicative of the potential pathogenicity of these species. One hemolysin (TC\# 1.C.126.1.2) seems to be encoded only by Bde.

\section{Holins (TC Subclass 1.E)}

Holins, encoded by bacterial spp. and their phage, can play a variety of roles in bacterial physiology, including biofilm formation, cell lysis, virulence, and release of toxins [Saier and Reddy, 2015]. In addition, these proteins have been associated with the probiotic potential of other Gram-positive bacteria, including Lactobacillus species
Zafar/Saier Jr. 
[Saier and Reddy, 2015]. Only the Bad strain seems to lack holins, while the other species have 1-6 of these proteins per organism, with Bli having the largest number of these proteins. Only Ban has homologs of the putative 3-4 TMS Transglycosylase-Associated Holin (T-A Hol) family (TC\# 1.E.43); functions of proteins belonging to this family are not well understood. Bbi and Bca have one homologue each of the SPP1 Holin family (TC\# 1.E.31), members of which may cause cell death in other bacteria via cell membrane disruption [Aunpad and Panbangred, 2012].

Other families of holins represented in the bifidobacterial species include the Mycobacterial 4 TMS Phage Holin (MP4 Holin) family (TC\# 1.E.40), the Listeria phage A118 Holin (Hol118) family (TC\# 1.E.21), and the bacteriophage Dp-1 Holin (Dp-1 Holin) family (TC\# 1.E.24). The presence of homologs of holins from different families is interesting and could indicate that these proteins have diverse functions in organisms important to human health, including those examined here.

\section{Secondary Carriers (TC Subclass 2.A)}

The numbers of secondary carriers in the nine species range from 48 to 105 per organism, with Ban having the least and Bde having the most. Proteins of the Major Facilitator Superfamily (MFS; TC\# 2.A.1) are well represented across the nine species, with numbers ranging from 18 to 48. Five species (Bbr, Bde, Bli, Bll, and Bps) have members of the Sugar Porter family (TC\# 2.A.1.1). Also, members of the Drug: $\mathrm{H}^{+}$Antiporter-1 (12 Spanner; DHA1) family (TC\# 2.A.1.2) and the Drug: $\mathrm{H}^{+}$Antiporter-2 (14 Spanner; DHA2) family (TC\# 2.A.1.3) are present in all nine bifidobacteria. Only Bad and Bde have a homologue of TC\# 2.A.1.2.21; a multidrug resistance protein that in Escherichia coli confers resistance to fluoroquinolones [Nishino and Yamaguchi, 2001]. Interestingly, all nine species seem to have lincomycin-resistance proteins (TC\# 2.A.1.3.30) that mediate the efflux of this antibiotic. Four species (Ban, Bde, Bli, and Bps) each have a homolog of TC\# 2.A.1.3.22, which has been shown to be a tetracycline efflux protein. Homologs of the multidrug efflux pump (TC\# 2.A.1.3.39) seem to be present in eight species (Bad, Bbi, Bbr, Bca Bde, Bli, Bll, and Bps); this protein in Staphylococcus exports various antimicrobials, including chloramphenicol, linezolid, and trimethoprim [Floyd et al., 2010]. Only Bll seems to have a macrolide efflux pump (TC\# 2.A.1.21.22). Seven species (Bad, Ban, $\mathrm{Bbi}, \mathrm{Bbr}, \mathrm{Bca}, \mathrm{Bde}$, and Bps) have one homologue each of TC\# 2.A.1.46.5, a putative quinolone resistance protein of the Uncharacterized Major Facilitator-5 (UMF5) family
(TC\# 2.A.1.46). Based on sequence similarity, members of this family are likely to be MDR efflux pumps, although additional functions, such as secondary metabolite export, may also be catalyzed by these proteins.

Members of the Glycoside-Pentoside-Hexuronide (GPH):cation symporter family (TC\# 2.A.2) are present in all nine of the species examined. Proteins of this family catalyze the uptake of sugars (mostly, but not exclusively, glycosides) together with a monovalent cation $\left(\mathrm{H}^{+}\right.$ or $\mathrm{Na}^{+}$; for references, see the TCDB). Similarly, all nine species seem to have proteins of the Amino Acid-Polyamine-Organocation (APC) superfamily (TC\# 2.A.3), members of which catalyze the uptake of amino acids and their derivatives [Schweikhard and Zeigler, 2012]. Bde has the most APC superfamily members, indicating that it may be more adept in using external amino acids for protein synthesis and energy generation in comparison to the other bifidobacterial species. The presence of these transporters also gives a competitive advantage in the acquisition of nutrients from the surroundings. As Bde is also an oral pathogen, these transporters may help it outcompete other bacterial species in the oral cavity. Also, Bde seems to be more resistant to low $\mathrm{pH}$ conditions, as it encodes a homolog of TC\# 2.A.3.7.1, a glutamate: $\gamma$ aminobutyrate antiporter that plays a potential role in acid neutralization. Due to their anatomical locations in the body, both Bde (oral resident), and Ban (found in the gut as well as breast milk) may face more acidic environments compared to the other species. As an oral pathogen, Bde must withstand a $\mathrm{pH}$ of 5.5, the critical point at which enamel breaks [Ventura et al., 2009]. These observations concerning the acidic tolerance of Bde are in accordance with a previous report [Ventura et al., 2009].

With the exception of $\mathrm{Bca}$, the remaining species have a homologue of the Cation Diffusion Facilitator (CDF) family (TC\# 2.A.4), with the hit protein (TC\# 2.A.4.1.1) being a heavy metal $\left(\mathrm{Cd}^{2+}, \mathrm{Zn}^{2+}, \mathrm{Co}^{2+}\right)$ efflux permease. Interestingly, only Bde has a homolog of the ResistanceNodulation-Cell Division (RND) superfamily (TC\# 2.A.6). RND pumps contribute to metal ion and antimicrobial resistance, as they pump antimicrobial compounds and heavy metals out of the cell [Fujisaki et al., 1996]. The absence of such RND pumps indicates that these species may utilize other drug efflux pumps to confer antimicrobial resistance as confirmed in other parts of this report.

Members of the Multidrug/Oligosaccharidyl-lipid/ Polysaccharide (MOP) flippase superfamily (TC\# 2.A.66) are present in all nine species. Four constituent families represented in the nine bifidobacterial species include the 
Multi Antimicrobial Extrusion (MATE) family (TC\# 2.A.66.1), the Polysaccharide Transport (PST) family (TC\# 2.A.66.2), the Oligosaccharidyl-Lipid Flippase (OLF) family (TC\# 2.A.66.3), and the Mouse Virulence Factor (MVF) family (TC\# 2.A.66.4). It is noteworthy that Ban is the only species that lacks a member of the MATE family. With the exception of Bli, the $\mathrm{K}^{+}$Uptake Permease (KUP) family (TC\# 2.A.72) is also represented in these bifidobacteria.

Additional families of secondary carriers that function in molecular export rather than uptake were found in the nine species. These include the Auxin Efflux Carrier (AEC) family (TC\# 2.A.69), the L-Lysine Exporter (LysE) family (TC\# 2.A.75), the Branched Chain Amino Acid Exporter (LIV-E) family (TC\# 2.A.78), the Threonine/ Serine Exporter (ThrE) family (TC\# 2.A.79), and the Putative Sulfate Exporter (PSE) family (TC\# 2.A.98). The substrates of these families are diverse, as noted by the family names, and it is likely that these transporters protect Bifidobacterium spp. against high toxic levels of these compounds.

\section{Primary Active Transporters (TC\# 3.A)}

The best represented superfamily of ATP hydrolysisdriven transporters in the nine bifidobacterial spp., based on numbers of proteins, is the ATP-Binding Cassette (ABC) superfamily (TC\# 3.A.1). Bad has 114 such proteins, Ban has 102, Bbi has 75, Bbr has 151, Bca 121, Bde 179, Bli 178, Bll 113, and Bps 123. It should be noted, however, that most of these systems are multicomponent, so the actual numbers of transport systems are much lower. The high numbers and the variety of these proteins in the bifidos indicate the robust uptake and efflux potential of these bacteria. As ABC transporters form a major fraction of the protein transportome of these species, it is safe to assume that ATP plays a pivotal role in the metabolism of these organisms, specifically, possibly that these species prefer fermentative mechanisms over oxidative mechanisms for generating energy. Since ABC systems are generally high-affinity systems compared to secondary carriers, these bacteria may live in environments in which the concentrations of metabolites are often low $(<100 \mathrm{nM})$.

All nine bifidobacterial species have members of the Carbohydrate Uptake Transporter-1 (CUT1) family (TC\# 3.A.1.1), members of which usually transport hexoses and/or oligosaccharides. Bde has the most such systems with 56 proteins. All of the species contain complete systems of an oligosaccharide (raffinose and stachyose) transporter (TC\# 3.A.1.1.53), which takes up oligosaccharides that are non-digestible by the human host
(NDOs). The presence of such systems in bifidobacteria suggests that these gut residents can utilize NDOs, which gives them a competitive advantage over most other gut microbes for colonization.

Systems of the ABC-type Polar Amino Acid Uptake Transporter (PAAT) family (TC\# 3.A.1.3) are present in all of these species. They seem to have complete glutamate porters (TC\# 3.A.1.3.9). Proteins of the Hydrophobic Amino Acid Uptake Transporter (HAAT) family (TC\# 3.A.1.4) are also encoded by each species. Seven species seem to have complete systems of TC\# 3.A.1.4.10, a branched chain, aliphatic, hydrophobic, amino acid transporter, which is important for the virulence of the Gram-positive pathogen Streptococcus pneumoniae [Basavanna et al., 2009]. The presence of homologs of this transporter is interesting as it may indicate the presence of a potential pathogenicity factor that is unrecognized in this specie. Members of the Peptide/Opine/Nickel Uptake Transporter (PepT) family (TC\# 3.A.1.5) are also present in all nine bifidobacterial species. Some members of this family can take up oligosaccharides (see the TCDB for references). Interestingly, proteins of the Polyamine/ Opine/Phosphonate Uptake Transporter (POPT) family (TC\# 3.A.1.11) are present only in Bad, Bli, and Bde. Bde has homologs of all components of a putative polyamine (spermidine/putrescine) uptake porter (TC\# 3.A.1.11.9), a transporter believed to be involved (perhaps indirectly) in the translocation of DNA [Sun, 2018]. The polyamines transported by members of the POPT family play numerous physiological roles in bacterial spp., such as chromosomal stabilization, biosynthesis of siderophores, cell growth, and biofilm formation [Wortham et al., 2007]. All strains examined here have components of putative thiamine transporters (TC\# 3.A.1.17.13) of the Taurine Uptake Transporter (TauT) family (TC\# 3.A.1.17) [Rodionova et al., 2015].

Prokaryotic ABC efflux systems (TC\# 3.A.1.100 to 3.A.1.199) have similar patterns in all nine species. Various drug exporters seem to be present in these bifidobacteria. The substrates of these exporters are likely to include tetracycline, erythromycin, lincomycin, oleandomycin, and other drugs.

All of these species possess F-type ATPases (TC\# 3.A.2) for energy ( $p m f$ vs. ATP) interconversion as expected. An important feature of these systems is the reversibility of the reaction catalyzed by these enzyme complexes, for either the establishment of a proton motive force (pmf) at the expense of ATP hydrolysis, or for ATP synthesis at the expense of the pmf [Abrahams et al., 1994; Chan et al., 2010].
36

Microb Physiol 2022;32:30-44 DOI: $10.1159 / 000518954$
Zafar/Saier Jr. 
Proteins of the P-type ATPase (P-ATPase) superfamily (TC\# 3.A.3) are present in all nine species, ranging from 4 to 13 such systems per organism. Bad, Ban, and Bbi have four such proteins with substrate specificities for $\mathrm{Ca}^{2+}, \mathrm{Cu}^{2+}, \mathrm{Pb}^{2+}$, and $\mathrm{Fe}^{2+}$. Bll and Bde each have two systems specific for $\mathrm{Ca}^{2+}$. The presence of more diverse Ptype ATPase transporters in these species may indicate an enhanced ability to tolerate low environmental $\mathrm{K}^{+}$concentrates as well as heavy metal stresses.

The general protein secretory (Sec) pathway seems to be functional in all nine species, as $4-5$ components of TC\# 3.A.5.2.2 were identified per organism. This was expected since all living organisms appear to possess the essential constituents of this protein secretion/membrane insertion system. It is important to note that some of the constituents of the well-characterized E. coli Sec system are not essential [Cao and Saier, 2003].

Decarboxylation-Driven Transporters (TC Subclass 3.B) Proteins of TC subclass 3.B are present in all nine bifidobacterial species, with each species having at least one $\mathrm{Na}^{+}$-transporting carboxylic acid decarboxylase family member (TC\# 3.B.1). These systems couple substrate decarboxylation to the extrusion of sodium ions [Balsera et al., 2011]. They provide a unique way to generate a sodium ion gradient (smf) [Boiangiu et al., 2005].

\section{Oxidoreduction-Driven Transporters (TC Subclass 3.D)}

Bifidobacterium spp., capable of anaerobic growth, can use either anerobic respiration or fermentation for energy generation. Complete systems of $\mathrm{H}^{+}$-transporting $\mathrm{NADH}$ /NADP transhydrogenases (TC\# 3.D.2.2.2) are present in all nine species. The presence of members of the Proton-Translocating Transhydrogenase (PTH) family (TC\# 3.D.2) and components of the Prokaryotic Succinate Dehydrogenase (SDH) family (TC\# 3.D.10) indicate that constituents of these proton pumping complexes are present in these primarily anaerobic organisms.

\section{Possible Group Translocators (TC Class 4)}

With the exception of Ban, all species have homologs of the phosphoenol-pyruvate:sugar phosphotransferdriven group translocators (PTS) (TC\# 4.A). All of the species (except Ban) seem to have one such translocator (TC\# 4.A.1.2.18), a glucose/fructose/glucosamine/mannose PTS group translocator. On the other hand, Bbi and Bbr have ten proteins of TC\# 4.A, meaning that they have many more PTS transporters at their disposal for uptake of a variety of sugars than is true for the other species. It is interesting to note that lactic acid firmicutes have ex- ceptionally large numbers of PTS sugar uptake systems [Barabote and Saier, 2005].

Members of Acyl CoA ligase-coupled transporters (TC\# 4.C) are present in all of the species with a range of $4-5$ proteins each. These use the energy of ATP to thio-esterify fatty acids and other organic acids such as carnitine in processes believed to often be coupled to uptake [Jia et al., 2007]. This role in group translocation is not fully accepted by all experts in the field, and many acyl-CoA ligases clearly do not function directly in transport [Reue, 2007].

Five species (Bbi, Bbr, Bca, Bde, and Bll) have polysaccharide synthase/exporters (TC\# 4.D). These putative enzyme/porters have exopolysaccharide synthesis activity that is believed to be coupled to polysaccharide secretion [Davis, 2012]. Exopolysaccharides are considered to be important players in biofilm formation and can also mediate cross-talk between bacterial spp. and their hosts [Ghafoor et al., 2011]. Prior literature on the exopolysaccharides synthesized by Bifidobacterium species shows that these surface molecules can also modulate the host's immune system and the intestinal microbiomes. They can also antagonize pathogenic residents of the gut $[\mathrm{Hi}-$ dalgo-Cantabrana et al., 2014]. All nine of the species examined have constituents of the lysylphosphatidylglycerol synthase/flippases (TC\# 4.H); members of this family can confer resistance to cationic antimicrobial agents [Ernst and Peschel, 2011].

\section{Auxiliary Transport Proteins (TC Subclass 8.A)}

Proteins belonging to this TC subclass facilitate the transport of molecules across the membrane but are not directly involved in the transport process. All of the bifidobacterial species possess members of various families of this subclass. All nine species have members of the Immunophilin-Like Prolyl:Peptidyl Isomerase Regulator (IPPI) family (TC\# 8.A.11).

\section{Incompletely Characterized Transport Systems (TC Class 9)}

The nine bifidobacterial species considered here have 24-40 such proteins. Interestingly, four species (Bad, Ban, $\mathrm{Bca}$, and Bli) have one homolog each of the Ferrous Iron Uptake family (TC\# 9.A.8), in agreement with the anaerobic nature of these organisms. The lack of members of this family in the remaining species is interesting and indicates that these organisms use other mechanisms for $\mathrm{Fe}^{2+}$ uptake.

All of these species have components of TC\# 9.A.47.2.2, a system of the Tight Adherence (Pilus) Biogenesis Apparatus (TABA) family (TC\# 9.A.47). Protein systems belonging to this family have roles in pilus subunit export 
Table 4. Overview of predicted substrate specificities of transporters in the nine Bifidobacterium species considered here

\begin{tabular}{lllllllllll}
\hline \multirow{2}{*}{ Substrate category } & \multicolumn{7}{l}{ Numbers of transport proteins/organism/category } & \\
\cline { 2 - 10 } & Bad & Ban & Bbi & Bbr & Bca & Bde & Bli & Bll & Bpa \\
\hline Inorganic anions & 10 & 17 & 15 & 18 & 17 & 22 & 25 & 18 & 18 \\
Inorganic cations & 24 & 28 & 25 & 22 & 24 & 34 & 26 & 27 & 26 \\
Amino acids & 40 & 32 & 15 & 37 & 40 & 43 & 38 & 37 & 37 \\
Non-selective & 33 & 28 & 30 & 37 & 33 & 80 & 58 & 34 & 40 \\
Drugs & 17 & 13 & 11 & 17 & 16 & 21 & 19 & 14 & 15 \\
Nucleobases, nucleosides, nucleotides & 7 & 4 & 8 & 8 & 6 & 17 & 4 & 6 & 8 \\
Proteins, peptides & 17 & 17 & 18 & 21 & 26 & 27 & 28 & 26 & 21 \\
Sugars and sugar derivatives & 32 & 27 & 21 & 67 & 40 & 33 & 51 & 41 & 49 \\
Lipids & 5 & 3 & 6 & 5 & 5 & 7 & 4 & 4 & 4 \\
Unknown & 88 & 84 & 91 & 118 & 94 & 119 & 127 & 101 & 93 \\
\hline Total & $\mathbf{2 7 3}$ & $\mathbf{2 5 3}$ & $\mathbf{2 4 0}$ & $\mathbf{3 5 0}$ & $\mathbf{3 0 1}$ & $\mathbf{4 0 3}$ & $\mathbf{3 8 0}$ & $\mathbf{3 0 8}$ & $\mathbf{3 1 1}$ \\
\hline
\end{tabular}

in bacterial species. Moreover, pilus-like structures have been shown to be encoded by various strains of Bifidobacterium species [Foroni et al., 2011; O'Connell Motherway et al., 2011]. These proteins probably assist the organisms in gut colonization due to their interactions with receptors on the surfaces of their mammalian host cells.

Only Bbr and Bli have lantibiotic immunity proteins of the putative MlbJ/Q Lantibiotic NAI-107 Immunity Protein (MLIP) family (TC\# 9.A.12). Lantibiotics are antimicrobial peptides released primarily by Gram-positive bacteria, and they cause pore-formation in the cell membranes of target bacteria [Bierbaum and Sahl, 2009]. The presence of the lantibiotic immunity proteins means that Bbr and Bli are probably insensitive to the toxic effects of the lantibiotic(s) they encode.

With the exception of Bad, the remaining bifidobacterial species have proteins of the Death Effector Domain A (DedA) family (TC\# 9.B.27); members of this family have been shown to contribute to membrane homeostasis in various bacterial species [Doerrler et al., 2013]. With the exception of $\mathrm{Bbi}$, these species have proteins of the putative protease component of the MusEFGKI ABC Transporter (MusI) family (TC\# 9.B.28). All of the species seem to have a protein (TC\# 9.B.146.1.6) of the Putative Undecaprenyl-Phosphate N-Acetylglucosaminyl Transferase (MurG) family (TC\# 9.B.46). These glycosyltransferases are associated with peptidoglycan synthesis.

\section{Overview of Substrates Transported by the}

Bifidobacterium Species

The substrate specificities of transporters found in all nine species are tabulated in Table 4 . The range of inor- ganic cationic transporters in the species is $22-34$, which indicates that the processes of osmotic regulation, ionic homeostasis, and heavy metal resistance are similar, possibly nearly the same in the nine bifidos. The numbers of inorganic anion transporters (10-25) in these species are less than those of the cationic porters, with fluoride $\left(\mathrm{Fl}^{-}\right)$ exporters and chloride $\left(\mathrm{Cl}^{-}\right)$uptake porters being the major inorganic anion transporters.

Amino acid transporters have been linked to virulence of some bacterial spp. [Stenz et al., 2011; Jung et al., 2012; Tanaka et al., 2018]. In this context, Bbi has the smallest number (15) of such proteins, while the range of such proteins otherwise is $32-43$ in the remaining species. This could possibly suggest reduced pathogenicity of Bbi in comparison to the others. Transport of amino acids in bacterial spp. is central to metabolic fitness in almost any ecological niche. The low number of such proteins in Bbi may indicate a disadvantage in gut colonization.

With regards to vitamin transporters, only Blo has a recognized protein specific for thiamine transport; this cofactor is an essential component of various physiological processes in bacteria such as carbohydrate and nucleotide metabolism [Costliow and Degnan, 2017]. However, it is required in such small amounts that uptake via transporters of low specificity may suffice to provide the required amounts of this vitamin. In contrast, research by [Rodionov et al., 2019] predicted various potential transporters for thiamine and niacin in bifidos. However, in agreement with our results, they also observed transport proteins for riboflavin and biotin in all of the strains included in this study. Likewise, we identified riboflavin and biotin transporters in all of the species included in this study.
38

Microb Physiol 2022;32:30-44 DOI: $10.1159 / 000518954$
Zafar/Saier Jr. 
Table 5. Numbers and percentages of proteins in the major families/superfamilies identified in nine Bifidobacterium species

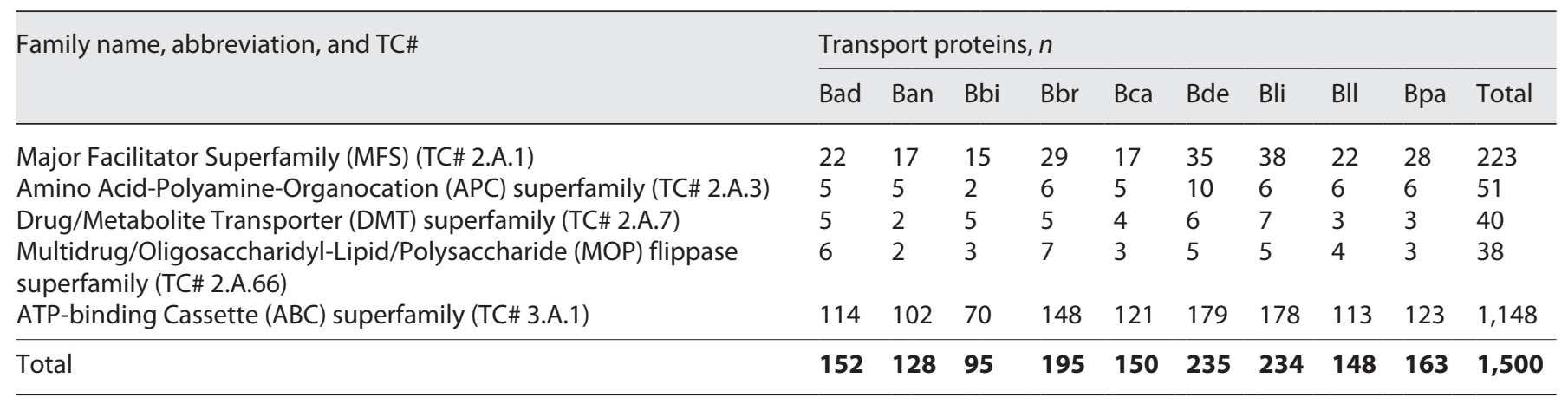

The number of sugar transporters is 21-67, with Bbi having the least and Bbr having the most such proteins. Among the nine species, Ban has the smallest overall number of transport proteins with unknown function (84), while the numbers of such proteins identified for the remaining organisms are 88-127.

It is known that many gut microbes, including probiotic species, possess many multi-drug resistance transporters and other proteins to help render antibiotics less effective. The highest number of drug exporters is present in Bde, having 21 such proteins. Bde is a resident of the oral cavity and gastrointestinal tract (GIT) in humans, and it seems to have a well-equipped "resistome," one that exceeds those of the other species. By contrast, Bbi seems to have the smallest number of drug export proteins (11) among the nine species.

\section{Major Superfamilies in the Nine Bifidobacterium Species}

The two most highly represented superfamilies in the nine species are the Major Facilitator Superfamily (MFS; TC\# 2.A.1), and the ATP-Binding Cassette (ABC) superfamily (TC\# 3.A.1), with details for each strain provided in Table 5 . The range of proteins of the MFS (TC\# 2.A.1) is between 15 and 38. Proteins of the ABC superfamily (TC\# 3.A.1) comprise the largest number within the transportomes of all nine species with a range of 70-179 per organism. However, it is important to note that while MFS transporters are usually single component systems, particularly in prokaryotes, $\mathrm{ABC}$ transporters are usually multicomponent systems and furthermore, the membrane constituents of $A B C$ systems, in contrast to MFS systems, are polyphyletic [Wang et al., 2009; Thomas et al., 2020]. Thus, the numbers of MFS porters is similar to those of the ABC porters, but the numbers of homologous membrane MFS proteins exceeds the numbers of any one type of $A B C$ membrane proteins.

The three other major superfamilies listed in Table 5 include the Amino Acid-Polyamine-Organocation (APC) superfamily (TC\# 2.A.3), the Drug/Metabolite Transporter (DMT) superfamily (TC \#2.A.7), and the Multidrug/Oligosaccharidyl-Lipid/Polysaccharide (MOP) flippase superfamily (TC \#2.A.66). However, these three families, all secondary carriers, only include a range of 2-10 proteins per organism.

\section{Discussion}

The human gut microbiome has been subject to extensive research over the past 3 decades. Recent advances in bioinformatics, metagenomics, and proteomics have unveiled extensive data about the functions and interactions of the bacterial residents among themselves and their mammalian hosts. These microbes can directly affect human health by exerting positive effects as probiotic organisms, and negative effects as pathogens. However, the roles of these microbes as probiotics, commensals, and potential pathogens are governed by various factors including their metabolic repertoire, presence of pathogenicity factors including some transport proteins, and their geographical location in the host [Wexler, 2007].

Bifidobacterium is the predominant bacterial genus represented in the breast-fed infant gut [Makino, 2018]. Their presence in the adult and infant gut is an indicator of a healthy gut microbiome [83). Members of this genus are dominant indigenous members of the mammalian gut; hence, the term "autochthonous bacteria" may be applied to them [Klijn et al., 2005]. Both Lactobacillus and Bifidobacterium are the most commonly used probiotic organisms in humans, and major probiotic formulations 
used in humans include strains belonging to these two genera [Ciorba, 2012].

All nine species included in this study encode PFTs; some of the toxins identified have antibacterial and antifungal properties. The antifungal properties of Bifidobacterium spp. have been reported [Ghazvini et al., 2016]. These toxic proteins may also function in the killing of other bacterial residents of the gut, including pathogens trying to colonize in close proximity to these microbes. As some of the bifidobacterial toxins have the potential to damage mammalian cells, these proteins can be considered as potential pathogenicity factors. It is noteworthy that these toxins could be more potent pathogenicity factors when these organisms translocate to other anatomical locations in the human body, that is, outside of the gut.

Prophage-like elements with similarity to holins (small transmembrane "hole-forming" proteins) have been reported in Bbr and Blo [Ventura et al., 2005], and we identified many more probable holins in these and other bifidobacteria (see online suppl. Table S1). The presence of holins in eight of the nine species (excluding only Bad) suggests that these proteins may contribute to either the probiotic or pathogenic potential (or both) of these organisms.

Numerous sugar uptake transporters are encoded within the genomes of the nine species, and these are required for the utilization of various carbohydrates. Bbi encodes the smallest number (21) of proteins involved in carbohydrate transport. These results are in accordance with Turroni et al. [2012], who predicted sugar transporters for the same Bbi strain and compared them with other bifidos. They predicted that the Bbi strain has 25 proteins for carbohydrate transport. Bbi has also been predicted to digest the O-glycans of mucins which are normally not degraded by enteric bacteria. This gives $\mathrm{Bbi}$ a competitive edge in colonization of the gut in comparison to other gut bacteria lacking this metabolic machinery [Turroni et al., 2012]. Bifidos spend a majority of their lifespan in the GIT of humans and other animals, which is an environment full of complex carbohydrates derived both from the diet and the host epithelial cells. Therefore, the ability of these species to induce the expression of genes encoding transporters for the utilization of these complex carbohydrates is important enhancing their competitiveness and adaptive abilities [Khoroshkin et al., 2016].

Overall, in comparison to results obtained in our previous study on Lactobacillus [Zafar and Saier, 2020], transporters of antimicrobial peptides (such as bacterio- cins) are less common in the bifidobacterial species examined here. Moreover, previous studies had suggested that the ability of Bifidobacterium spp. to synthesize lantibiotics (bacteriocins that contain unusual amino acids such as dehydrated amino acids as well as lanthionine residues) [Lee et al., 2011] may play a role in their probiotic activities [Arboleya et al., 2016]. However, in our analyses, only the Bbr genome seems likely to encode the enzymes for lantibiotic biosynthesis. Future analyses will help to determine if other bifidobacteria can produce such compounds.

Many lactic acid bacteria, including Bifidobacterium species, produce various vitamins, including some $B$ vitamins that are essential for growth. The vitamins that seem to be taken up by the nine bifidobacterial species include riboflavin $\left(\mathrm{B}_{2}\right)$ and biotin $\left(\mathrm{B}_{7}\right)$. It has been shown that some bifidobacteria have an absolute requirement for both of these vitamins [Deguchi et al., 1985], and the presence of transport proteins capable of importing these two vitamins in the nine strains included in this study corroborates this claim.

A comparative analysis of the results of the present communication with our previous studies on E. coli strains and Salmonella, Bacteroides and Lactobacillus species unveils similarities and differences in the transporters encoded among the different types of organisms. The percentages of $\alpha$-channels in the Bifidobacterium spp. are 4.5-5.4\% compared to 3.4-4.2\% for E. coli and Salmonella, 2.9-5.4\% for Bacteroides, and 2.7-4.8\% for Lactobacillus. PFTs accounted for $1.2-2.5 \%$ for Bifidobacterium strains, while in the previous studies these toxins accounted for $0.2-1.4 \%$ in E. coli and Salmonella, $0.3-0.9 \%$ for Bacteroides, and $0.7-2.3 \%$ for the lactobacilli. The higher percentage of PFTs in the bifidobacteria investigated in the current study is interesting, and as most of these species have a basic probiotic nature, the presence of PFTs may indicate unrecognized pathogenic potential. Also, the percent of holins encoded within the bifidobacterial genomes $(0-1.5 \%)$ is comparable to these values in the other species: Salmonella and E. coli $(0.8-1.3 \%)$, Bacteroides (0.5-0.8\%), and Lactobacillus (0-1.9\%). Eliminating the genes encoding these small proteins and/or the PFTs may allow the engineering of probiotic strains that lack pathogenic characteristics altogether [Douillard and de Vos, 2019; Zuo et al., 2020].

The average percentages of secondary porters in the Bifidobacterium spp. (range between 19 and 26\%) is somewhat lower than the average percentages recorded for previously examined strains (E. coli and Salmonella, 27.4$32.5 \%$; Lactobacillus, $20.4-35.6 \%$, but nearly the same as
40

Microb Physiol 2022;32:30-44 DOI: $10.1159 / 000518954$
Zafar/Saier Jr. 
for Bacteroides, 20-26.6\%). However, the nine Bifido species examined in this study have a high percentage range (42.5-51.3\%) of primary pyrophosphate hydrolysis-driven transport proteins (TC subclass 3.A), a value that is much higher than what we had found for E. coli and Salmonella (26.9-32.5\%) or Bacteroides (20.3-26.6\%), although it is similar to that for the lactobacilli (35.9-55.7\%). In the three species, Bad, Bde and Bli, the percent of such transport proteins exceeds $50 \%$ of the overall transportome. The higher numbers of such transport proteins in both genera (Bifidobacterium and Lactobacillus) suggests that these organisms have a metabolic edge over their microbial neighbors for nutrient acquisition (higher affinities and greater concentration gradient generation) and consequently exhibit advantages for colonization within the largely anaerobic shared ecological niches of the human gut.

The percent of oxidoreduction-driven transporters was found to be $1.4-2.9 \%$ for the bifidobacteria and $0-1.7 \%$ for the lactobacilli. As species belonging to both genera are primarily fermentative, these low numbers are understandable. Moreover, the combined percent of such transporters in the more heterotrophic strains is $4.1-5.9 \%$ for $E$. coli/Salmonella and 4.7-6.7\% for Bacteroides spp. Additionally, the bifidobacteria have similar percentages of recognized transporters of unknown biochemical mechanism (0.5-1.8\%) compared to E. coli/Salmonella (0.8-1.2\%), and Bacteroides (0.3-1.1\%), although these percentages are much lower than those of the lactobacilli (5.6-11.4\%). In agreement with observations recorded for our previously examined genome projects, the transportomes of the bifidobacteria seem to be finely tuned according to their organismal lifestyles (probiotic, pathogenic, and/or commensal, as well as extracellular vs. intracellular).

In the Bifidobacterium spp. examined here, the transport proteins comprise $12.3-19.3 \%$ of the total proteome. These numbers are higher than reported in our previous studies although in all such studies we used the same methodologies. For example, the range of percentages for the Lactobacillus strains was $4.5-17.9 \%$, and that for the Bacteroides species was $8.8-14.1 \%$.

Previous reports suggested that Bbi and Bli are most prevalent in the infant gut, while Bbi and Bad predominate in the adult gut. This shift in species distribution with respect to human age groups may be attributed to genome/transportome contexts. For instance, Bbi and Bli have carbohydrate transporters for human milk oligosaccharides, while Bad and Bll have a repertoire of transporters for carbohydrates in adult food sources.

The biochemical properties of bifidobacteria together with evidence linking these organisms to human health have encouraged the development of approaches to stimulate the growth and/or activities of bifidobacteria in the colon, the so-called "bifidogenic effect," through diet. One strategy to selectively increase the prevalence of bifidobacteria in the colon is through the consumption of human nondigestible food components, termed "prebiotics" [Sharifi-Rad et al., 2020]. As the present species have efficient sugar-transporting repertoires as shown in this communication and others [Pokusaeva et al., 2011; Arzamasov et al., 2018; Fushinobuand Abou Hachem, 2021]. It is recommended that the use of prebiotics such as poly- and oligosaccharides containing fructose (fructooligosaccharides), galactose (galacto-oligosaccharides), glucose (malto-oligosaccharides), xylose (xylo-oligosaccharides), and arabinose and xylose (arabinoxylans and arabinoxylan-oligosaccharides) could increase the population of bifidos in the human gut [Flint et al., 2012]

The overall transportomes of the bifidobacteria unveil pivotal features of their metabolic repertoire, probiotic potential, and potential for pathogenicity. These features, taken into consideration, must influence the relationships of these organisms not only to their hosts, but also to their bacterial competitors. Of note is the reduced genome sizes of all nine bifidobacterial species, which correlates with their reduced biosynthetic capabilities. The drug exporters observed in these probiotic species are certainly of interest with regards to the use of antibiotics to counteract diseases related to mammalian health. Further analyses will help us understand the mechanisms of antibacterial resistance that may still be unknown for some or all of these species. Moreover, the high numbers of sugar, amino acid, and protein transporters should benefit these organisms in niche adaptation. As some of these organisms may colonize different anatomical sites within the oral cavity, vagina, and gut, they could encounter a variety of nutrients, and in such a context the aforementioned transporters would be essential players.

Within the context of our previous and present proteome analysis projects concerning the microbial residents of the human gut, our emphasis has been to determine transport proteins that assist these bacterial species in their probiotic and/or pathogenic roles. In this regard, the PFTs may be important players, as they not only have antibacterial and antifungal effects, but they can also cause damage to mammalian cells. We hypothesize the same is true for some or all of the nine bifidobacteria, which can use these toxins as a part of their probiotic repertoire. However, in some instances, their toxins could cause detrimental effects to host cells as well. Further studies through genetic manipulation will allow us to in- 
crease our understanding of the roles these toxins play, and they may also allow the development of safer probiotic Bifidobacterium strains.

The trillions of microbial residents in the human gut are in constant contact with their host tissues and microbial neighbors. In such competitive and cooperative environments, only those species will survive and flourish that have efficient transportomes appropriate for their specific niches. This study, in conjunction with our previous genome projects on gut bacteria, discloses valuable insight about the roles of the transportomes in the context of the gut microbiome. The findings of this study will help genetic engineers to generate altered species of Bifidobacterium with increased probiotic attributes and decreased pathogenic potential.

\section{Acknowledgements}

We appreciate the help of Pranavsai Iddamsetty and Kevin Hendargo in performing the analyses used in this study.

\section{Statement of Ethics}

This research was exempt from ethical committee approval as there was no use of any animal/human samples/subjects during this study.

\section{Conflict of Interest Statement}

The authors have no conflicts of interest to declare. One of the authors (M.H.S.) is an editor-in-chief of Microbial Physiology.

\section{Funding Sources}

This work was supported by grant GM077402 from the US National Institutes of Health.

\section{Author Contributions}

Both H.Z and M.H.S. contributed to the conception of this project. H.Z. performed the research and wrote the original draft. M.H.S reviewed and edited the manuscript. Both authors approved the manuscript for publication.

\section{Data Availability Statement}

All data generated or analyzed during this study are included in this article and the supplementary material files. Further enquiries can be directed to H.Z.

\section{References}

Abdel-Megeed RM. Probiotics: a promising generation of heavy metal detoxification. Biol Trace Elem Res. 2021;199(6):2406-13.

Abrahams JP, Leslie AG, Lutter R, Walker JE. Structure at 2.8 A resolution of F1-ATPase from bovine heart mitochondria. Nature. 1994;370(6491):621-8.

Arboleya S, Watkins C, Stanton C, Ross RP. Gut bifidobacteria populations in human health and aging. Front Microbiol. 2016;7: 1204.

Arzamasov AA, van Sinderen D, Rodionov DA. Comparative genomics reveals the regulatory complexity of bifidobacterial arabinose and arabino-oligosaccharide utilization. Front Microbiol. 2018;9:776.

Aunpad R, Panbangred W. Evidence for two putative holin-like peptides encoding genes of Bacillus pumilus strain WAPB4. Curr Microbiol. 2012;64(4):343-8.

Balsera M, Buey RM, Li XD. Quaternary structure of the oxaloacetate decarboxylase membrane complex and mechanistic relationships to pyruvate carboxylases. J Biol Chem. 2011; 286(11):9457-67.
Barabote RD, Saier MH Jr. Comparative genomic analyses of the bacterial phosphotransferase system. Microbiol Mol Biol Rev. 2005;69(4): 608-34.

Basavanna S, Khandavilli S, Yuste J, Cohen JM, Hosie AH, Webb AJ, et al. Screening of Streptococcus pneumoniae $\mathrm{ABC}$ transporter mutants demonstrates that LivJHMGF, a branched-chain amino acid $\mathrm{ABC}$ transporter, is necessary for disease pathogenesis. Infect Immun. 2009;77(8):3412-23.

Bierbaum G, Sahl HG. Lantibiotics: mode of action, biosynthesis and bioengineering. Curr Pharm Biotechnol. 2009;10(1):2-18.

Bintsis T. Lactic acid bacteria as starter cultures: an update in their metabolism and genetics. AIMS Microbiol. 2018;4(4):665-84.

Boiangiu CD, Jayamani E, Brügel D, Herrmann G, Kim J, Forzi L, et al. Sodium ion pumps and hydrogen production in glutamate fermenting anaerobic bacteria. J Mol Microbiol Biotechnol. 2005;10(2-4):105-19.
Bozkurt HS, Quigley EM. The probiotic Bifidobacterium in the management of coronavirus: a theoretical basis. Int J Immunopathol Pharmacol. 2020;34:2058738420961304.

Bullen CL, Tearle PV, Willis AT. Bifidobacteria in the intestinal tract of infants: an in-vivo study. J Med Microbiol. 1976;9(3):325-33.

Butta H, Sardana R, Vaishya R, Singh KN, Mendiratta L. Bifidobacterium: an emerging clinically significant metronidazole-resistant anaerobe of mixed pyogenic infections. Cureus. 2017;9(4):e1134.

Cao TB, Saier MH Jr. The general protein secretory pathway: phylogenetic analyses leading to evolutionary conclusions. Biochim Biophys Acta. 2003;1609(1):115-25.

Chan H, Babayan V, Blyumin E, Gandhi C, Hak $\mathrm{K}$, Harake $\mathrm{D}$, et al. The p-type ATPase superfamily. J Mol Microbiol Biotechnol. 2010; 19(1-2):5-104.

Ciorba MA. A gastroenterologist's guide to probiotics. Clin Gastroenterol Hepatol. 2012;10(9): 960-8. 
Collado MC, González A, González R, Hernández M, Ferrús MA, Sanz Y. Antimicrobial peptides are among the antagonistic metabolites produced by Bifidobacterium against Helicobacter pylori. Int J Antimicrob Agents. 2005; 25(5):385-91.

Costliow ZA, Degnan PH. Thiamine acquisition strategies impact metabolism and competition in the gut microbe Bacteroides thetaiotaomicron. mSystems. 2017;2(5).

Cukrowska B, Bierła JB, Zakrzewska M, Klukowski M, Maciorkowska E. The relationship between the infant gut microbiota and allergy. The role of Bifidobacterium breve and prebiotic oligosaccharides in the activation of antiallergic mechanisms in early life. Nutrients. 2020;12(4):946.

Davis JK. Combining polysaccharide biosynthesis and transport in a single enzyme: dual-function cell wall glycan synthases. Front Plant Sci. 2012;3:138.

Deguchi Y, Morishita T, Mutai M. Comparative studies on synthesis of water-soluble vitamins among human species of Bifidobacteria. Agr Biol Chem. 1985(49):13-9.

Do J, Zafar H, Saier MH Jr. Comparative genomics of transport proteins in probiotic and pathogenic Escherichia coli and Salmonella enterica strains. Microb Pathog. 2017;107: 106-15.

Doerrler WT, Sikdar R, Kumar S, Boughner LA New functions for the ancient DedA membrane protein family. J Bacteriol. 2013;195(1) 3-11.

Douillard FP, de Vos WM. Biotechnology of health-promoting bacteria. Biotechnol Adv. 2019;37(6):107369.

Dudek-Wicher R, Junka A, Paleczny J, Bartoszewicz M. Clinical trials of probiotic strains in selected disease entities. Int J Microbiol. 2020; 2020:8854119.

Ernst CM, Peschel A. Broad-spectrum antimicrobial peptide resistance by MprF-mediated aminoacylation and flipping of phospholipids. Mol Microbiol. 2011;80(2):290-9.

Esaiassen E, Hjerde E, Cavanagh JP, Simonsen GS, Klingenberg C. Norwegian Study Group on invasive bifidobacterial I. Bifidobacterium bacteremia: clinical characteristics and a genomic approach to assess pathogenicity. J Clin Microbiol. 2017;55(7):2234-48.

Fernandez L, Pannaraj PS, Rautava S, Rodriguez JM. The microbiota of the human mammary ecosystem. Front Cell Infect Microbiol. 2020 10:586667.

Floyd JL, Smith KP, Kumar SH, Floyd JT, Varela MF. LmrS is a multidrug efflux pump of the major facilitator superfamily from Staphylococcus aureus. Antimicrob Agents Chemother. 2010;54(12):5406-12.

Flint HJ, Scott KP, Duncan SH, Louis P, Forano E. Microbial degradation of complex carbohydrates in the gut. Gut Microbes. 2012;3(4): 289-306.

Foroni E, Serafini F, Amidani D, Turroni F, He F, Bottacini $\mathrm{F}$, et al. Genetic analysis and morphological identification of pilus-like struc- tures in members of the genus Bifidobacterium. Microb Cell Fact. 2011;10(Suppl 1): S16.

Fujisaki S, Ohnuma S, Horiuchi T, Takahashi I, Tsukui S, Nishimura Y, et al. Cloning of a gene from Escherichia coli that confers resistance to fosmidomycin as a consequence of amplification. Gene. 1996;175(1-2):83-7.

Fukuda S, Toh H, Hase K, Oshima K, Nakanishi $\mathrm{Y}$, Yoshimura K, et al. Bifidobacteria can protect from enteropathogenic infection through production of acetate. Nature. 2011; 469(7331):543-7.

Fushinobu S, Abou Hachem M. Structure and evolution of the bifidobacterial carbohydrate metabolism proteins and enzymes. Biochem Soc Trans. 2021;49(2):563-78.

Ghafoor A, Hay ID, Rehm BH. Role of exopolysaccharides in Pseudomonas aeruginosa biofilm formation and architecture. Appl Environ Microbiol. 2011;77(15):5238-46.

Ghazvini RD, Kouhsari E, Zibafar E, Hashemi SJ, Amini A, Niknejad F. Antifungal activity and aflatoxin degradation of Bifidobacterium bifidum and Lactobacillus fermentum against toxigenic Aspergillus parasiticus. Open Microbiol J. 2016;10:197-201.

Green SL. Case report: fatal anaerobic pulmonary infection due to Bifidobacterium eriksonii. Postgrad Med. 1978;63(3):187-92.

Hidalgo-Cantabrana C, Sánchez B, Milani C, Ventura M, Margolles A, Ruas-Madiedo P. Genomic overview and biological functions of exopolysaccharide biosynthesis in Bifidobacterium spp. Appl Environ Microbiol. 2014;80(1):9-18.

Ikeda M, Arai M, Lao DM, Shimizu T. Transmembrane topology prediction methods: a re-assessment and improvement by a consensus method using a dataset of experimentallycharacterized transmembrane topologies. In Silico Biol. 2002;2(1):19-33.

Iscla I, Wray R, Blount P. An in vivo screen reveals protein-lipid interactions crucial for gating a mechanosensitive channel. FASEB J. 2011; 25(2):694-702.

Jia Z, Pei Z, Maiguel D, Toomer CJ, Watkins PA. The fatty acid transport protein (FATP) family: very long chain acyl-CoA synthetases or solute carriers? J Mol Neurosci. 2007;33(1): 25-31.

Jung H, Hilger D, Raba M. The Na+/L-proline transporter PutP. Front Biosci. 2012;17:74559.

Khoroshkin MS, Leyn SA, Van Sinderen D, Rodionov DA. Transcriptional regulation of carbohydrate utilization pathways in the Bifidobacterium genus. Front Microbiol. 2016;7: 120.

Klijn A, Mercenier A, Arigoni F. Lessons from the genomes of bifidobacteria. FEMS Microbiol Rev. 2005;29(3):491-509.

Kosmerl E, Rocha-Mendoza D, Ortega-Anaya J, Jiménez-Flores R, García-Cano I. Improving human health with milk fat globule membrane, lactic acid bacteria, and bifidobacteria. Microorganisms. 2021;9(2):341.
Lee JH, Li X, O'Sullivan DJ. Transcription analysis of a lantibiotic gene cluster from Bifidobacterium longum DJO10A. Appl Environ Microbiol. 2011;77(17):5879-87.

Lee JH, O'Sullivan DJ. Genomic insights into bifidobacteria. Microbiol Mol Biol Rev. 2010; 74(3):378-416

Los FC, Randis TM, Aroian RV, Ratner AJ. Role of pore-forming toxins in bacterial infectious diseases. Microbiol Mol Biol Rev. 2013;77(2): 173-207.

Makino H. Bifidobacterial strains in the intestines of newborns originate from their mothers. Biosci Microbiota Food Health. 2018;37(4): 79-85.

Matsuki T, Pédron T, Regnault B, Mulet C, Hara T, Sansonetti PJ. Epithelial cell proliferation arrest induced by lactate and acetate from Lactobacillus casei and Bifidobacterium breve. PLoS One. 2013;8(4):e63053.

Mayer MP, Bukau B. Hsp70 chaperones: cellular functions and molecular mechanism. Cell Mol Life Sci. 2005;62(6):670-84

Morita $\mathrm{H}$, Toh H, Oshima K, Nakano A, Yamashita $\mathrm{N}$, Iioka $\mathrm{E}$, et al. Complete genome sequence of Bifidobacterium catenulatum JCM 1194(T) isolated from human feces. J Biotechnol. 2015;210:25-6.

Nakajo K, Takahashi N, Beighton D. Resistance to acidic environments of caries-associated bacteria: Bifidobacterium dentium and Bifidobacterium longum. Caries Res. 2010;44(5):431-7.

Nishino K, Yamaguchi A. Analysis of a complete library of putative drug transporter genes in Escherichia coli. J Bacteriol. 2001;183(20) 5803-12.

Nolan LS, Rimer JM, Good M. The role of human milk oligosaccharides and probiotics on the neonatal microbiome and risk of necrotizing enterocolitis: a narrative review. Nutrients. 2020;12(10):3052.

O'Callaghan A, van Sinderen D. Bifidobacteria and their role as members of the human gut microbiota. Front Microbiol. 2016;7:925.

O'Connell Motherway M, Zomer A, Leahy SC, Reunanen J, Bottacini F, Claesson MJ, et al. Functional genome analysis of Bifidobacterium breve UCC2003 reveals type IVb tight adherence (Tad) pili as an essential and conserved host-colonization factor. Proc Nat Acad Sci U S A. 2011;108(27):11217-22.

Pokusaeva K, Fitzgerald GF, van Sinderen D. Carbohydrate metabolism in Bifidobacteria. Genes Nutr. 2011;6(3):285-306.

Pool-Zobel BL, Neudecker C, Domizlaff I, Ji S, Schillinger U, Rumney C, et al. Lactobacillusand bifidobacterium-mediated antigenotoxicity in the colon of rats. Nutr Cancer. 1996 26(3):365-80.

Price MN, Arkin AP. PaperBLAST: text mining papers for information about homologs. mSystems. 2017;2(4):e00039-17.

Rajesh T, Jeon JM, Kim YH, Kim HJ, Yi da H, Park $\mathrm{SH}$, et al. Functional analysis of the gene SCO1782 encoding Streptomyces hemolysin (S-hemolysin) in Streptomyces coelicolor M145. Toxicon. 2013;71:159-65. 
Reddy VS, Saier MH Jr. BioV Suite - a collection of programs for the study of transport protein evolution. FEBS J. 2012;279(11):2036-46.

Reue $\mathrm{K}$. The role of lipin 1 in adipogenesis and lipid metabolism. Novartis Found Symp. 2007;286:58-203.

Rodionov DA, Arzamasov AA, Khoroshkin MS, Iablokov SN, Leyn SA, Peterson SN, et al. Micronutrient requirements and sharing capabilities of the human gut microbiome. Front Microbiol. 2019;10:1316.

Rodionova IA, Li X, Plymale AE, Motamedchaboki K, Konopka AE, Romine MF, et al. Genomic distribution of B-vitamin auxotrophy and uptake transporters in environmental bacteria from the Chloroflexi phylum. Environ Microbiol Rep. 2015;7(2):204-10.

Ruiz-Gonzalez C, Roman P, Rueda-Ruzafa L, Rodriguez-Arrastia M, Cardona D. Effects of probiotics supplementation on dementia and cognitive impairment: a systematic review and meta-analysis of preclinical and clinical studies. Prog Neuropsychopharmacol Biol Psychiatry. 2020:110189.

Saier MH Jr, Reddy BL. Holins in bacteria, eukaryotes, and archaea: multifunctional xenologues with potential biotechnological and biomedical applications. J Bacteriol. 2015; 197(1):7-17.

Samanta S. Potential impacts of prebiotics and probiotics in cancer prevention. Anticancer Agents Med Chem. 2020. doi: 10.2174/18715 20621999201210220442.

Schweikhard ES, Ziegler CM. Amino acid secondary transporters: toward a common transport mechanism. Curr Top Membr. 2012;70:1-28.

Sela D, Garrido D, Lerno L, Shai W, Tan K, et al. Bifidobacterium longum subsp. infantis ATCC $15697 \alpha$-fucosidases are active on fucosylated human milk oligosaccharides. Appl Environ Microbiol.. 2012;78(3):795-803.

Shang J, Wan F, Zhao L, Meng X, Li B. Potential immunomodulatory activity of a selected strain Bifidobacterium bifidum H3-R2 as evidenced in vitro and in immunosuppressed mice. Front Microbiol. 2020;11:2089.

Sharif S, Meader N, Oddie SJ, Rojas-Reyes MX, McGuire W. Probiotics to prevent necrotising enterocolitis in very preterm or very low birth weight infants. Cochrane Database Syst Rev. 2020;10:CD005496.

Sharifi-Rad J, Rodrigues CF, Stojanović-Radić Z, Dimitrijević M, Aleksić A, Neffe-Skocińska K, et al. Probiotics: versatile bioactive components in promoting human health. Medicina. 2020;56(9):433.

Stenz L, Francois P, Whiteson K, Wolz C, Linder $\mathrm{P}$, Schrenzel J. The CodY pleiotropic repressor controls virulence in gram-positive pathogens. FEMS Immunol Med Microbiol. 2011; 62(2):123-39.
Stockbridge RB, Robertson JL, KolmakovaPartensky L, Miller C. A family of fluoridespecific ion channels with dual-topology architecture. Elife. 2013;2:e01084

Sugahara H, Odamaki T, Fukuda S, Kato T, Xiao JZ, Abe F, et al. Probiotic Bifidobacterium longum alters gut luminal metabolism through modification of the gut microbial community. Sci Rep. 2015;5:13548.

Sun D. Pull in and push out: mechanisms of horizontal gene transfer in bacteria. Front Microbiol. 2018;9:2154

Tanaka KJ, Song S, Mason K, Pinkett HW. Selective substrate uptake: the role of ATP-binding cassette $(A B C)$ importers in pathogenesis. Biochim Biophys Acta Biomembr. 2018; 1860(4):868-77.

Tang F, Saier MH Jr. Transport proteins promoting Escherichia coli pathogenesis. Microb Pathog. 2014;71-72:41-55.

Tavan E, Cayuela C, Antoine JM, Trugnan G, Chaugier C, Cassand P. Effects of dairy products on heterocyclic aromatic amine-induced rat colon carcinogenesis. Carcinogenesis. 2002; 23(3):477-83.

Thomas C, Aller SG, Beis K, Carpenter EP, Chang $\mathrm{G}$, Chen L, et al. Structural and functional diversity calls for a new classification of $\mathrm{ABC}$ transporters. FEBS Lett. 2020;594(23):376775.

Tiwari SK, Dicks LMT, Popov IV, Karaseva A, Ermakov AM, Suvorov A, et al. Probiotics at war against viruses: what is missing from the picture? Front Microbiol. 2020;11:1877.

Toh H, Hayashi J, Oshima K, Nakano A, Takayama Y, Takanashi K, et al. Complete genome sequence of Bifidobacterium dentium strain JCM 1195T, isolated from human dental caries. Genome Announc. 2015;3(2):e00284-15.

Turroni F, Bottacini F, Foroni E, Mulder I, Kim $\mathrm{JH}$, Zomer A, et al. Genome analysis of Bifidobacterium bifidum PRL2010 reveals metabolic pathways for host-derived glycan foraging. Proc Natl Acad Sci U S A. 2010;107(45): 19514-9.

Turroni F, Strati F, Foroni E, Serafini F, Duranti S, van Sinderen D, et al. Analysis of predicted carbohydrate transport systems encoded by Bifidobacterium bifidum PRL2010. Appl Environ Microbiol. 2012;78(14):5002-12.

van de Guchte M, Penaud S, Grimaldi C, Barbe V, Bryson K, Nicolas P, et al. The complete genome sequence of Lactobacillus bulgaricus reveals extensive and ongoing reductive evolution. Proc Natl Acad Sci U S A. 2006; 103(24):9274-9.

Ventura M, Lee JH, Canchaya C, Zink R, Leahy S, Moreno-Munoz JA, et al. Prophage-like elements in bifidobacteria: insights from genomics, transcription, integration, distribution, and phylogenetic analysis. Appl Environ Microbiol. 2005;71(12):8692-705.

Ventura M, Turroni F, Zomer A, Foroni E, Giubellini V, Bottacini F, et al. The Bifidobacterium dentium $\mathrm{Bd} 1$ genome sequence reflects its genetic adaptation to the human oral cavity. PLoS Genet. 2009;5(12):e1000785.
Vitetta L, Vitetta G, Hall S. Immunological tolerance and function: associations between intestinal bacteria, probiotics, prebiotics, and phages. Front Immunol. 2018;9:2240.

Wang B, Dukarevich M, Sun EI, Yen MR, Saier $\mathrm{MH}$ Jr. Membrane porters of ATP-binding cassette transport systems are polyphyletic. J Membr Biol. 2009;231(1):1-10.

Walter B, Küspert M, Ansorge D, Krämer R, Burkovski A. Dissection of ammonium uptake systems in Corynebacterium glutamicum: mechanism of action and energetics of AmtA and AmtB. J Bacteriol. 2008;190(7): 2611-4.

Weber E, Reynaud Q, Suy F, Gagneux-Brunon A, Carricajo A, Guillot A, et al. Bifidobacterium species bacteremia: risk factors in adults and infants. Clin Infect Dis. 2015;61(3):482-4.

Wexler HM. Bacteroides: the good, the bad, and the nitty-gritty. Clin Microbiol Rev. 2007; 20(4):593-621.

Wicinski M, Gebalski J, Golebiewski J, Malinowski B. Probiotics for the treatment of overweight and obesity in humans - a review of clinical trials. Microorganisms. 2020;8(8): 1148.

Wong CB, Odamaki T, Xiao JZ. Insights into the reason of human-residential bifidobacteria (HRB) being the natural inhabitants of the human gut and their potential health-promoting benefits. FEMS Microbiol Rev. 2020; 44(3):369-85.

Wortham BW, Patel CN, Oliveira MA. Polyamines in bacteria: pleiotropic effects yet specific mechanisms. Adv Exp Med Biol. 2007; 603:106-15.

Xiao Y, Zhai Q, Zhang H, Chen W, Hill C. Gut colonization mechanisms of Lactobacillus and Bifidobacterium: an argument for personalized designs. Annu Rev Food Sci Technol. 2021;12:213-33.

Yuan L, van der Mei HC, Busscher HJ, Peterson BW. Two-stage interpretation of changes in TEER of intestinal epithelial layers protected by adhering bifidobacteria during E. coli challenges. Front Microbiol. 2020;11:599555.

Zafar H, Saier MH Jr. Comparative genomics of transport proteins in seven Bacteroides species. PLoS One. 2018;13(12):e0208151.

Zafar H, Saier MH Jr. Comparative genomics of the transport proteins of ten Lactobacillus strains. Genes. 2020;11(10):1234.

Zhai Y, Saier MH Jr. A web-based program (WHAT) for the simultaneous prediction of hydropathy, amphipathicity, secondary structure and transmembrane topology for a single protein sequence. J Mol Microbiol Biotechnol. 2001;3(4):501-2.

Zuo F, Chen S, Marcotte H. Engineer probiotic bifidobacteria for food and biomedical applications - current status and future prospective. Biotechnol Adv. 2020;45:107654. 